\title{
A LINGUISTIC LANDSCAPE IN PURWOKERTO: POWER AND SOLIDARITY STAND STRONG IN A CULINARY CENTER
}

\author{
Eko Pamuji, Khristianto \\ Universitas Muhammadiyah Purwokerto \\ pamuji.eko25@gmail.com, kristian.topz@gmail.com
}

\begin{abstract}
The article explores a linguistics landscape along a street in Purwokerto in which diverse people display their identity as a marketing tool for their foods. They display phenomena of monolingualism, bilingualism, or multilingualism. The brands they create include a person's name, an origin area, and English term with a single purpose of selling. The name can stand for power and authority and the origin can stand for the solidarity. The worldly word represents a prestige and a certain social class. Thus, the phenomena are obvious evidence of how power and solidarity have merged into the brands as their strategy in marketing.
\end{abstract}

Keywords: linguistics landscape, power, solidarity

\section{Introduction}

Many parts in Purwokerto have their own special values that make them different from one to another. An existence of a new road can lead into an area where an industry grows and develops. In another case, as a road is widened to ease the traffic through an urban facilities, it gradually changes into a center of culinary business. Surely, this development is an effect of other external factors like contemporary cultures in this country where outdoor leisure time has emerged as a necessary agenda for an Indonesian family.

One of such destinations for the need is Soeharso street in Purwokerto. It is the street leading to the town's sport centers and conventions where special and regular events are conducted, attracting the people to visit periodically. With the obvious potential market, business players then try their luck to open their outlets along the street. Today has witnessed a rapidly growing businesses like the restaurants, eateries, cafes, hotel, and even street vendors. Besides its strategic location, the atmosphere there is quite cool, supported with its medium traffic, making the area an ideal place to enjoy lunch breaks or a nice dining at in the early evening.

The establishment of business places at the street cannot be separated from the existence of the media to market their products for the prospective buyers. They function to make potential buyers interested to visit their places by applying certain marketing strategy. The strategy is "an organized function and the process of creating, introducing, communi- cating, and delivering a message and value to the customers in order to make them interested, thus the company will get the benefits" (Rajan: 2009). Marketing can be done in various ways and it cannot be separated from the use of language. One of them is creating a name or brand for the product. With this, they try to create a brand as a hallmark of their business. In addition, they also make use of slogans and advertisements as parts of the strategy.

The use of language in branding the business and the slogan is extremely vital in the marketing strategy to be known to the public. How they attract consumers is what makes me interested in exploring the landscape there. In this article, I want to go deeper by capturing the scene and extracting the language use seen in the street. The objects focused here are the banners and similar media displaying the brand and the product in the culinary businesses along the Suharso street. The data of language use was then analyzed based on the perspective of linguistics landscape, especially the view related to power and solidarity.

\section{Power and Solidarity in LL}

As Shohamy and Gorter in Iris (2014:2) state that linguistics landscape can be found anywhere and includes the use of language in society, the heard and spoken word, as well as the represented and displayed. By comprehending the heard and spoken words which are included as linguistics landscape, the researcher tries to combine what Backhaus (2006) explains about power and solidarity in 
the brands with the concepts of power and solidarity in multilingual community proposed by Formentelli, Hudson, Sequeiros in Abdely (2016).

Backhaus (2006:62) states that the power will be emerged only in official signs, meanwhile the solidarity is property of nonofficial signs. Hudson in Abdely (2016:3) explains that power usually indicates asymmetrical relationship where one speaker is subordinate to another in multilingual community. This implies that nonofficial signs are included into power. The linguistics markers of power and solidarity are not only ambiguous, implying either power or solidarity (Tannen and Kakava in Abdely (2006:3). Meanwhile, the solidarity always can be found in nonofficial signs which indicates symmetrical relationship characterized by social equality and similarity (Hudson in Abdely, 2006).
Employing the notions above, this article will discuss how Indonesian people, especially business players in Purwokerto make use of language to create the power and solidarity via language landscape--thus giving the impression of high solidarity to prospective buyers. Besides, it will simultaneously prove the power of language in positioning the product in the market, as a battle field of culinary industries.

\section{Survey on Soeharso street}

The survey was conducted in September, 2017 along the Soeharso street. It was done by taking pictures all names of shops and restaurants as samples of the research. There are 38 photos taken. They contain someone's name, someone's name and origin, slogan in Indonesian, stores and cafes name use English, or both.

Table 1. Brands Found in Culinary Spot

\begin{tabular}{|l|c|l|c|}
\hline \multicolumn{2}{|c|}{ Indonesian } & \multicolumn{2}{c|}{ English } \\
\hline \multicolumn{1}{|c|}{ Application } & Counted Sign & \multicolumn{1}{c|}{ Application } & Counted Sign \\
\hline Person's name & 10 & English name & 13 \\
\hline $\begin{array}{l}\text { Person's name } \\
\text { +origin }\end{array}$ & 10 & $\begin{array}{l}\text { Slogan in Eng- } \\
\text { lish }\end{array}$ & 1 \\
\hline Slogan in Indonesian & 4 & & \\
\hline
\end{tabular}

\section{Power Addressed as Prestige}

The target market in the center are generally the upper middle class. That is the reason for using English term as the brand; it will bring prestige. Viewed from a wider view, parts of their target are the foreigners living in the city for certain period or staying there as tourists; using English will help these people to easily find these brands. Seen in another way, it will impress the local people that the product does not belong to them, something coming from the other; they feel it is not their place (Abdely, 2016:3). After all, English has been common to find in the names of products sold in this country. The people have been familiar with it. Thus, using English will not make their products unknown for the public. Besides, the language has a certain association with "quality belief" which everybody wants and needs - whether or not they understand its meaning. I think this is the reason why shoes local products like Edward Forrer and Pakalolo decide the names.
As seen in Figure 1 in which Taiwan is mentioned as the origin of the food in English. As if the intended target is a Taiwanese or local people coming from the upper middle class. Meanwhile, the English use may mean "an expensive price" which then makes the customers of low middle class excluded. This indicates asymmetrical relationship where a group of people is subordinate to another group (Hudson in Abdely, 2016:3). The absence of slogan or advertisement aimed to attract buyers from various circle makes potential buyers fear of the price tag for a portion of Taiwanese cuisine.

A Similar phenomenon also occurs in various clothing stores, distros, where they only use English as the name and slogan. This indicates the western domination truly works in Indonesia, even in its small town like Purwokerto. The belief that the west means prestige and quality has been a norm. The items that are westward and untouched with local sense will frighten prospective buyers, as if only a classy buyer is worth shopping there. 

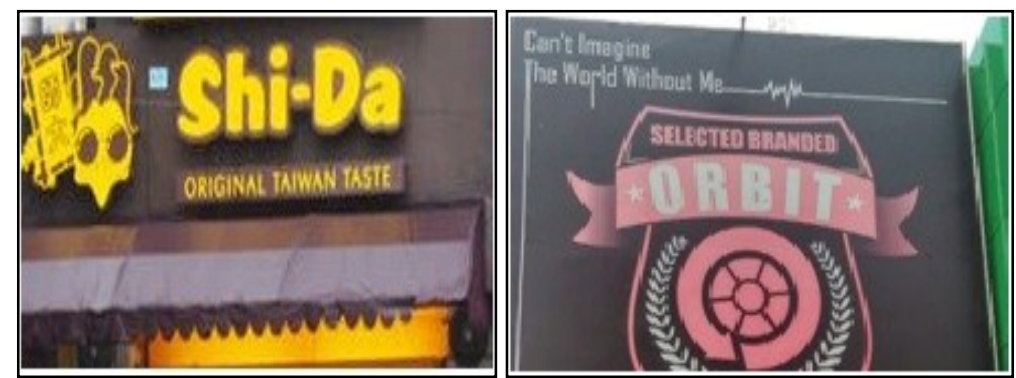

Figure 1. English terms in the display

Figure 2 shows a western brand of store or its imitative style which is created to borrow the western high prestige for Asian. The buyer feels no solidarity if buy in that store, except only expect recognition of prestige. While in Asia itself, the power is often linked to positive things that have kindness and mutual supportiveness, so as to create solidarity (Pye and Wetzel in Abdely, 2016:10). This is reflected in those who use their national language or even their local language for their brands.

\section{Solidarity Addressed by Name of Figure}

The use of a person's name as the name of the store, restaurants, eateries is not merely giving a common name, but there is a meaning and intention behind. Addressing another by a title, last name or by the first name is associated with solidarity (Tannen in Abdely, 2016). Name use will indicate symmetrical relationships by social equality and similarity (Hudson in Abdely, 2016). This linguistics phenomenon is also found in this area, 10 brands. An example is shown in Figure 3 where it uses the name "Bu Supri" (Mrs. Supri, colloquial addressee to Indonesian woman) to show a close distance between the seller and the buyer, because people surely want a sense of closeness to others (Sequeiros in Abdely, 2016).

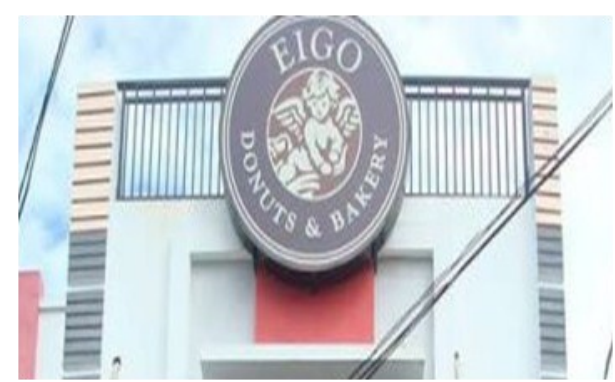

Figure 2. Imitative western product

By looking at the name, the buyer will feel close and intimate about the nickname before the first or last name, such as Mas means brother, Pak means sir/father, $B u$ means $\mathrm{mrs} / \mathrm{mom}$, or the title such as Haji (Hajj) which is familiar to everyone's ear as can be seen in Figure 4. Those nicknames are same with in Iraq which kinship terms are classified into superior kin which includes among many, yaba (grandfather), paga (grandmother), ma (mother), pa (father), and bakpema (senior father, i.e. father's older brother/cousin) (Abdely, 2016:5). In addition, they use a literal style in Indonesian, making it easily understood by prospective buyers. They intend to attract people's attention and convince them that they are brothers or families; customers then are expected not to embarrassed, hesitant, and they do not need to wor-
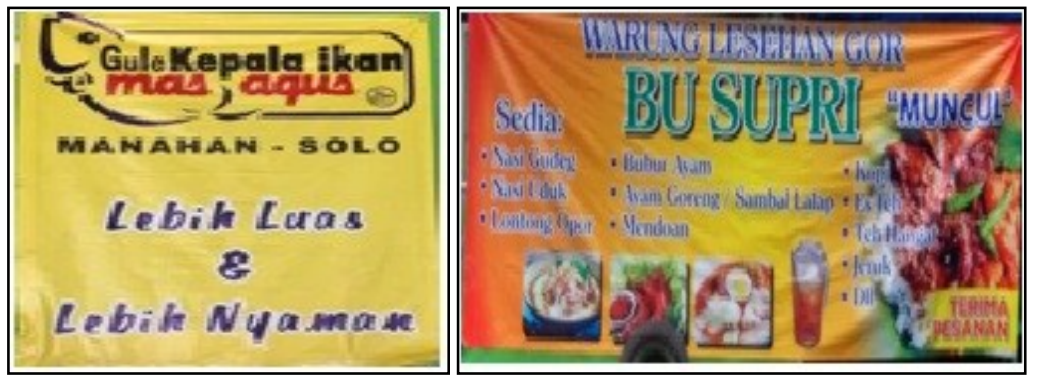

Figure 3. The solidarity through the use of nickname 
-ry about the price.

\section{Solidarity Addressed by Origin}

Purwokerto is also one of the densely populated cities occupied by people from other areas. It is inevitably that the phenomenon of the inclusion of the food origin or the pioneer is also included into the names of the restaurants and eateries. This inclusion indicates that those businesses mostly belong or run by the people from the place mentioned in the brand (Backhaus, 2006:63). An example can be observed on the Figure 4 which shows the region of Kertosuro as the origin of that food. People have known well that the name of $\mathrm{Be}$ bekGoreng (Fried Duckling) Haji Slamet is surely famous in Java, especially Central Java and Yogyakarta. The customers will not wonder on the taste and the price, though the real owner is not the person mentioned; he/she just share the right to sell through franchise scheme.
The similar fact also appears on Figure 5 when someone includes the name of Suramadu Bangkalan, which is in Madura. Madura is famous for being proficient in trading and roasting meat called "sate". The customers will think that the seller is the original "Madura" who is regarded to have a real skill in cooking delicious satay. Though the seller is not the original Madura, they use the name to convince that their food belongs to certain identity and culture or social community and they want to come close with the customers (Formentelli in Abdely, 2016:2). A similar case is seen in other brands displayed in Figure 5; all mention the area of origin to emphasize a genuine taste of the products.

\section{Conclusion}

The shop fronts and the displays as the marketing materials make a linguistics landscape in the culinary center. They use English term, local names, and name of origin area.

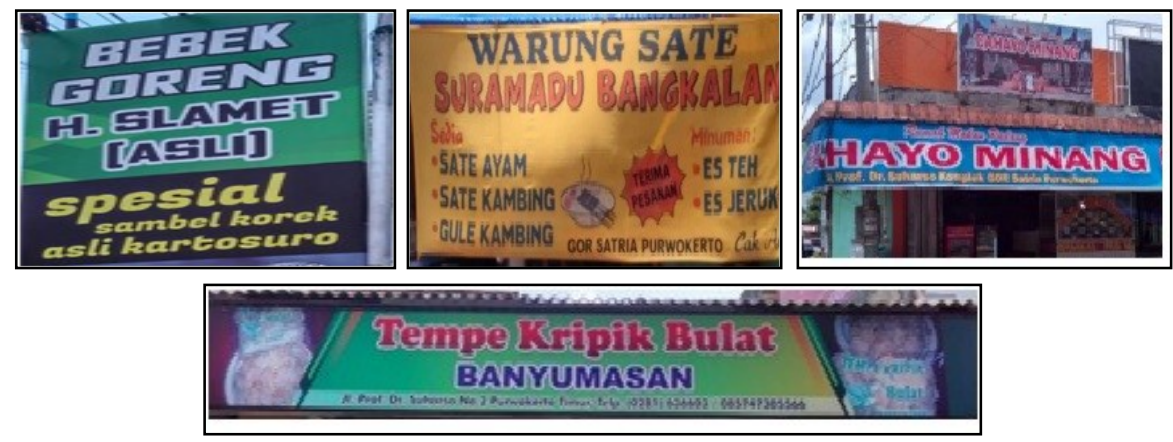

Figure 4 . The originality as the power

The various choices actually have a single purpose of selling. English word, or western style, emphasizes on the sense of prestige and quality. It is sensed that the west has an authority, or power, of good-guaranteed products. The names of person builds solidarity and closeness to the local people. The customers are framed with a familial atmosphere that the taste of the culinary sets provided are similar the ones cooked by their relatives, and the price is also friendly for them. The area of origin also presents an authority of power to certify the foods sold, convincing the market that they really serve the genuine flavor as it is in its origin.

\section{References}

Gorter, Durk. 2006. Linguistic landscape A New Approach to Multilingualism. Clevedon: Multilingual Matters LTD
Abdely, Ammar. 2016. Power and Solidarity in Social Interaction: A Review of Selected Studies. Ramadi: Journal and Language Communication

Yavari, Sonia. 2012. Linguistics Landscape and Language Policy: A Comparative Study of Linkoping University and ETH Zurich. Zurich

Varadarajan, Rajan. 2009. Strategic Marketing and Marketing Strategy: Domain, Definition, Fundamental Issues and Fundamental Premises. Academy of Marketing Science

Hewitt, Iris. 2014. Linguistics Landscape as Language Learning Literacy Resource in Caribbean Creole Context. Caribbean Education 